\title{
Combined effects of a third-generation bisphosphonate, zoledronic acid with other anticancer agents against murine
}

\section{osteosarcoma}

\author{
N Horie' ${ }^{1,2}$, H Murata*, , S Kimura ${ }^{3}$, H Takeshita', T Sakabe', T Matsui', T Maekawa ${ }^{3}$, T Kubo' and S Fushiki ${ }^{2}$ \\ 'Department of Orthopaedics, Graduate School of Medical Science, Kyoto Prefectural University of Medicine, 465 Kawaramachi-Hirokoji, Kamigyo-ku, \\ Kyoto 602-8566, Japan; 'Department of Pathology and Applied Neurobiology, Graduate School of Medical Science, Kyoto Prefectural University of \\ Medicine, 465 Kawaramachi-Hirokoji, Kamigyo-ku, Kyoto 602-8566, Japan; ${ }^{3}$ Department of Transfusion Medicine and Cell Therapy, Kyoto University \\ Hospital, 54 Kawahara-cho shogoin, Sakyo-ku, Kyoto 606-8507, Japan
}

\begin{abstract}
Bisphosphonates (BPs) are widely used to treat bone diseases and also appear to possess direct antitumour activity. We have previously reported that third-generation BPs such as zoledronic acid (ZOL) and minodronic acid (YM529) synergistically augment the effects of anticancer agents in various cancer cells. Recently, we have also reported the antitumour effects of YM529 on murine osteosarcoma cells. As YM529 has not been clinically available, we herein focused on the anti-osteosarcoma effects of ZOL which is clinically available. In addition to ZOL alone, we evaluated the concurrent or sequential combined effects of ZOL with other anticancer agents against murine osteosarcoma cell lines. ZOL showed almost same anti-osteosarcoma activity compared with YM529 and more sensitive growth inhibitory effects against osteosarcoma cells than normal cells. Moreover, ZOL acted synergistically in vitro when administered concurrently with paclitaxel (PAC) or gemcitabine (GEM), not only in wild-type osteosarcoma cells but also in P-glycoprotein (P-gp)-overexpressing osteosarcoma cells, which were much less sensitive against each anticancer agent. Furthermore, $24 \mathrm{~h}$ of ZOL pretreatment significantly augmented the sensitivity of doxorubicin (DOX), PAC or GEM against osteosarcoma cells. These findings suggest that combined administration of ZOL with other anticancer agents may improve the osteosarcoma treatment.
\end{abstract}

British Journal of Cancer (2007) 96, 255-26I. doi: I0.1038/sj.bjc.6603548 www.bjcancer.com

(c) 2007 Cancer Research UK

Keywords: osteosarcoma; bisphosphonates; zoledronic acid; combined effects

Osteosarcoma is a high-grade malignant bone neoplasm that occurs in children and adolescents. Recently, the prognosis of these patients has improved substantially owing to the development of various adjuvant chemotherapies. However, these chemotherapies are not fully effective and as a result, $20 \%$ of all osteosarcoma patients still die owing to tumour metastasis (Link, 1993; Unni, 1996; Bacci et al, 2006). As a consequence, various new osteosarcoma therapies have been investigated worldwide, with many clinical trials performed on novel agents.

Bisphosphonates (BPs) are widely used to treat bone diseases such as osteoporosis, which is caused by excessive bone resorption or metastatic bone involvement (Fleisch, 2002). We have previously reported that third-generation BPs such as zoledronic acid (ZOL) and minodronic acid YM529 show direct antitumour effects and synergistically augments the effects of anticancer agents in various cancer cell lines (Kuroda et al, 2003; Kimura et al, 2004; Matsumoto et al, 2005; Segawa et al, 2005; Yuasa et al, 2005). Recently, several investigators have reported the anti-

*Correspondence: Dr H Murata; E-mail: murah@koto.kpu-m.ac.jp Received 12 September 2006; revised 13 November 2006; accepted 22 November 2006 osteosarcoma effects of third-generation BPs in vitro (Evdokiou et al, 2003; Kubista et al, 2006; Kubo et al, 2006; Tenta et al, 2006) and in vivo (Heymann et al, 2005; Ory et al, 2005). We have also reported that YM175 and YM529 inhibit the growth of murine osteosarcoma cell lines in a time- and dose-dependent manner by preventing prenylation of small GTPases and might be subject to multi-drug resistance mechanism in osteosarcoma cells (Horie et al, 2006).

There are numerous reports concerning the combined effects of third-generation BPs with anticancer agents in various cancer cell lines. However, only Heymann et al (2005) reported the combined effect of ZOL with ifosfamide in osteosarcoma cell lines. As YM529 has not been clinically available, we herein focused on the antiosteosarcoma effects of ZOL which is clinically available. In addition to $\mathrm{ZOL}$ alone, we herein investigated the concurrent or sequential combined effects of ZOL against two murine osteosarcoma cell lines not only with commonly used agents for osteosarcoma such as doxorubicin (adriamycin, DOX), cisplatin (CDDP) and methotrexate (MTX) (Bacci et al, 2006) but also with novel agents such as imatinib mesylate (IM), paclitaxel (PAC) and gemcitabine (GEM) which have recently been analysed for osteosarcoma treatment (Verweij et al, 2000; McGary et al, 2002; Okuno et al, 2002). 


\section{MATERIALS AND METHODS}

\section{Reagents}

ZOL (1-hydroxy-2-(1H-imidazole-1-yl) ethylidene-bisphosphonic acid) and IM were obtained from Novartis Pharma AG (Basel, Switzerland). DOX (from Kyowa Hakko Kogyo Co. Ltd., Tokyo, Japan), CDDP (from Nihon Kayaku Co. Ltd., Kyoto, Japan), PAC (from Bristol-Myers Squibb, New York, USA) and GEM (from Eli Lilly KK, Kyoto, Japan) were provided by each company MTX, verapamil and ethylenediaminetetracetic acid (EDTA) were purchased from Sigma Aldrich (Tokyo, Japan). ZOL, DOX, IM and PAC were dissolved in $\mathrm{Ca}^{-} \mathrm{Mg}^{-}$phosphate-buffered saline (PBS). MTX was dissolved in $0.1 \mathrm{~N} \mathrm{NaOH}$ and then further diluted in PBS. All diluted solutions were stored at $-20^{\circ} \mathrm{C}$. Appropriate drug concentrations were made by dilution with fresh medium immediately before each experiment.

\section{Cell lines}

MOS cell line was established from the murine osteosarcoma model developed at Massachusetts General Hospital (Choi et al, 1979). P-glycoprotein (P-gp)-overexpressing cell line which was established by stepwise increments of DOX, MOS/ADR was generated as previously reported (Takeshita et al, 1996). Murine osteosarcoma cell line, LM8 was established from the murine Dunn osteosarcoma cell line (Asai et al, 1998). Normal human dermal fibroblasts (NHDF) cell line was purchased from Kurabo (Osaka, Japan). These cells were maintained in Dulbecco's modified Eagle's medium supplemented with $15 \mathrm{mM}$ HEPES buffer, $10 \%$ foetal bovine seruman antibiotic solution of penicillin $\left(100 \mathrm{U} \mathrm{ml}^{-1}\right)$ and streptomycin $\left(100 \mu \mathrm{g} \mathrm{ml}^{-1}\right)$. Normal murine osteoblast cells were isolated from murine skull bone as described elsewhere (Takahashi et al, 1988). These cells were maintained in $\alpha$-MEM supplemented with $10 \%$ foetal bovine serum and an antibiotic solution of penicillin $\left(100 \mathrm{U} \mathrm{ml}^{-1}\right)$ and streptomycin $\left(100 \mu \mathrm{g} \mathrm{ml}^{-1}\right)$. All cells were cultured at $37^{\circ} \mathrm{C}$ in a fully humidified incubator with $5 \%$ $\mathrm{CO}_{2}$. All experiments described were performed at least three times using cells in the exponential growth phase.

\section{Concurrent exposure to $\mathrm{ZOL}$ and other anticancer agents}

Proliferation of the cell lines was determined using the methylthiazol-diphenyl-tetrazolium (MTT) assay, as previously described (Hansen et al, 1989). MOS, MOS/ADR or LM8 and osteoblast or NHDF cells were cultivated in a flat-bottomed 96-well plate (Greiner Labortechnik, Frickenhausen, Germany) at $5 \times 10^{3}$ and $1 \times 10^{4}$ cells per well, respectively in $100 \mu \mathrm{l}$ of medium and incubated with various concentrations of $\mathrm{ZOL}$ alone or in combination with other anticancer agents such as DOX, CDDP, MTX, IM, PAC or GEM for $48 \mathrm{~h}$. The means of six data values for each treatment were calculated. For all the cell lines, we evaluated a linear relationship between the degree of proliferation and cell number within the range of the experiment. Half-maximal inhibition constants $\left(\mathrm{IC}_{50}\right)$ were determined using the nonlinear regression programme CalcuSyn (Biosoft, Cambridge, UK). To investigate the effect of combining ZOL with other anticancer agents, the MOS or LM8 cells were treated with six concentrations $\left(0.25,0.5,0.75,1.0,1.5\right.$ or $\left.2.0 \times \mathrm{IC}_{50}\right)$ of $\mathrm{ZOL}$ alone and ZOL combined with another anticancer agent. The fraction affected ( $\mathrm{Fa}$ ) (i.e. Fa of 0.25 is equivalent to $75 \%$ viable cells) and the combination index (CI) were calculated with CalcuSyn (Chow et al, 2000). This method enables quantification of synergism $(\mathrm{CI}<1)$ and antagonism $(\mathrm{CI}>1)$ at different dose and effect levels. Combination index calculations were made under the assumption that the mechanisms of drug action were not mutually exclusive.

\section{Sequential exposure of cells to ZOL and other anticancer agents}

We next investigated the effect of a sequential exposure regime with ZOL, followed by the other anticancer agents. MOS or LM8 cells were incubated in 96-well plates at a density of $1.5 \times 10^{3}$ in $100 \mu \mathrm{l}$ of medium per well for $24 \mathrm{~h}$, then incubated with $1.0 \mu \mathrm{M} \mathrm{ZOL}$ for MOS cells or $10 \mu \mathrm{M}$ ZOL for LM8 cells for $24 \mathrm{~h}$. After the osteosarcoma cells were washed thrice in PBS, the second anticancer agent was added to the respective wells. After a further $48 \mathrm{~h}$, the rate of growth inhibition was evaluated by MTT assay. Data from three independent experiments were collected and the Student's $t$-test was used to evaluate the efficacy of sequential treatment of ZOL and other agents and to compare the effects of each anticancer agent alone. $P$-values of less than 0.05 were considered statistically significant and were derived from twosided statistical tests.

\section{Cell cycle analysis}

To explore the possible mechanisms of combined effects of ZOL and other agents, MOS or LM8 cells were analysed for cell cycle alterations by staining with propidium iodide (Sigma Aldrich) after exposure to ZOL and/or anticancer agents for $24 \mathrm{~h}$, as previously described (Kimura et al, 1995). The stained nuclei were analysed using a FACSCalibur flow cytometry (Becton Dickinson, Japan). DNA histograms were created using Cell Quest ${ }^{\mathrm{TM}}$ software for Apple Macintosh (Becton Dickinson).

\section{RESULTS}

\section{Growth inhibitory effects of $\mathrm{ZOL}$ against murine osteosarcoma cells}

ZOL inhibited the growth of murine osteosarcoma cells dose dependently, whereas in normal cells such as murine osteoblast cells and human fibroblast cells, NHDF were much less sensitive to ZOL. Growth of MOS cells was not inhibited by up to $1000 \mu \mathrm{M}$ EDTA (Figure 1A). The $\mathrm{IC}_{50}$ values of $\mathrm{ZOL}$ for MOS, LM8, osteoblast and NHDF cells after $48 \mathrm{~h}$ exposure were 1.56, 7.36, 72.4 and $145.3 \mu \mathrm{M}$, respectively. ZOL showed almost same antiosteosarcoma activity compared with YM529 (Table 1).

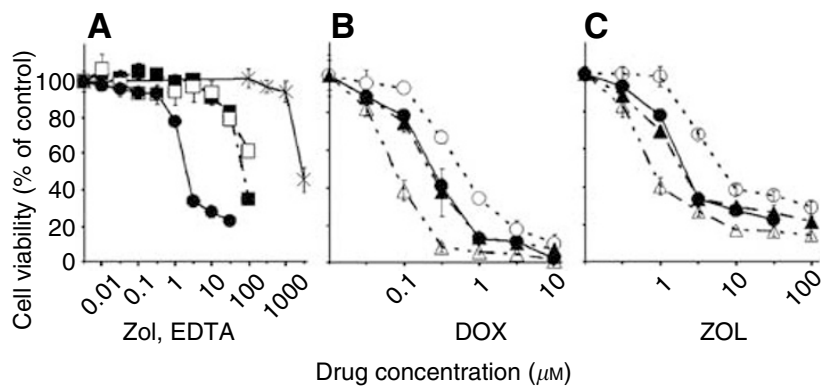

Figure I Effect of ZOL on growth of cells. (A) The ability of ZOL to inhibit the growth of the murine osteosarcoma MOS cells $(\mathbf{O})$, murine osteoblast cells $(\mathbf{\square})$ and human fibroblast cell line $(\square)$ was determined by MTT assay. And also, that of EDTA to inhibit the growth of MOS cells $(x)$ was determined. The ability of $\mathrm{DOX}(\mathbf{B})$ and $\mathrm{ZOL}(\mathbf{C})$ to inhibit the growth of the P-gp-overexpressing MOS/ADR cell line $(O)$ and its parental MOS cell line ( ) was determined by MTT assay. MOS/ADR cell line was 4.4 times more resistant to DOX than MOS cells and was also not as sensitive to ZOL. When cells were incubated with I $\mu \mathrm{M}$ of verapamil $(\mathbf{\Delta})$, the ability of DOX and ZOL to inhibit the growth of the MOS/ADR cell line became as sensitive as its parental MOS cell line. Furthermore, $10 \mu \mathrm{M}$ of verapamil $(\square)$ strengthened the inhibitory effect of these agents on the MOS/ADR cell line more than on the MOS cell line. 
Table I The $\mathrm{IC}_{50}{ }^{\mathrm{a}}$ values $(\mu \mathrm{m})$ of $\mathrm{ZOL}$ and anticancer agents in murine osteosarcoma cell lines

\begin{tabular}{lcccccccc}
\hline Agents & YM529 & ZOL & DOX & CDDP & MTX & IM & PAC & GEM \\
\hline LM8 & 6.20 & 7.36 & 0.30 & 11.0 & 0.12 & 5.6 & 0.025 & 0.32 \\
MOS & 1.22 & 1.56 & 0.19 & 16.9 & 0.039 & 15.0 & 0.048 & 0.21 \\
MOS/ADR & 5.90 & 7.10 & 0.82 & - & - & - & 0.16 & 0.89 \\
Resistance $^{\text {b }}$ & 4.8 & 4.6 & 4.4 & - & - & - & 3.3 & 4.2 \\
\hline
\end{tabular}

Values represent the means of at least three independent experiments. ${ }^{a} C_{50}=$ the

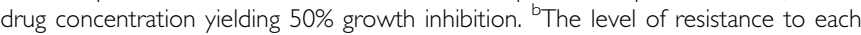
agent is expressed as the $I_{50}$ of MOS/ADR cells divided by the value of MOS cells. YM529 data have been reported elsewhere (Horie et al, 2006).

P-gp-overexpressing MOS/ADR cell line was 4.4 times more resistant to DOX than its parental MOS cell line (Table 1, Figure 1B). Similarly, MOS/ADR cells were not as sensitive to ZOL as MOS cells (Figure $1 \mathrm{C}$ ). The $\mathrm{IC}_{50}$ value of ZOL for the MOS/ADR cells after $48 \mathrm{~h}$ exposure was $7.10 \mu \mathrm{m}$ which was 4.6 times more resistant to ZOL than parental MOS cells (Table 1). We next examined the combined effects of a P-gp inhibitor, verapamil with ZOL against P-gp-overexpressing MOS/ADR cells. Verapamil $(1 \mu \mathrm{M})$ augmented the effects of ZOL on MOS/ADR cells and restored the sensitivity of MOS/ADR cells almost same as of parental MOS cells. Verapamil alone up to $30 \mu \mathrm{M}$ had no growthinhibitory effects on these cell lines (data not shown). These results suggested that ZOL may be influenced by P-gp related multi-drug resistance system in osteosarcoma cell lines.

Growth-inhibitory effects of other anticancer agents against osteosarcoma cells are summarised in Table 1.

\section{Concurrent combined effects of ZOL with other anticancer agents}

At first, we examined the combined effects of ZOL with commonly used agents for osteosarcoma such as DOX, CDDP and MTX. When combined with CDDP, the CIs at $\mathrm{Fa} 0.5$ and $\mathrm{Fa} 0.8$ were less than $1.0 \pm 1$ s.d. in both MOS and LM8 cells, except at Fa 0.5 for LM8 cells, indicating that the effects of combination with CDDP were synergistic rather than additive effects. DOX and MTX additively augmented the effects of ZOL (Table 2). Next, we explored the combined effects of ZOL with IM, PAC and GEM, which were expected to be novel agents for osteosarcoma. IM also showed additive effects with ZOL (Table 2). Interestingly, PAC and GEM demonstrated significant synergistic effects with ZOL not only in MOS and LM8, but also in P-gp-overexpressing cell line, MOS/ADR (Table 2, Figure 2).

\section{Sequential combined effects of ZOL with other anticancer agents}

Cytotoxic effects of DOX on both MOS (Figure 3A) and LM8 cells (Figure 4A) and of CDDP on LM8 cells (Figure 4B) were sinificantly enhanced by a $24 \mathrm{~h}$ pretreatment with ZOL $(P<0.05)$, whereas the cytotoxic effects of MTX were antagonised by the ZOL pretreatment of both osteosarcoma cell lines (Figures 3C and 4C). Cytotoxic effects of PAC on both MOS (Figure 3E) and LM8 cells (Figure 4E) and of GEM on LM8 cells (Figure 4F) were significantly enhanced by a $24 \mathrm{~h}$ pretreatment with ZOL $(P<0.05)$, whereas the cytotoxic effects of IM were affected significantly by ZOL pretreatment, neither in MOS (Figure 3D) nor in LM8 cells (Figure 4D).

\section{Alterations of cell cycle by ZOL, PAC or GEM alone}

As described above, the significant synergistic effects of PAC with ZOL was seen in both MOS and LM8 cells, and those of GEM were
Table 2 Combination indexes at $\mathrm{Fa} 0.50$ and 0.80 of $\mathrm{ZOL}$ in concurrent combination with other agents

\begin{tabular}{llll}
\hline Agents & Cell line & Cl at Fa $\mathbf{0 . 5}$ (Effect) & Cl at Fa $\mathbf{0 . 8}$ (Effect) \\
\hline DOX & MOS & $1.14 \pm 0.09$ (Antagonism) & $0.97 \pm 0.17$ (Additive) \\
& LM8 & $1.01 \pm 0.14$ (Additive) & $0.50 \pm 0.19$ (Synergism) \\
\multirow{2}{*}{ CDDP } & MOS & $0.35 \pm 0.06$ (Synergism) & $0.59 \pm 0.14$ (Synergism) \\
& LM8 & $0.83 \pm 0.24$ (Additive) & $0.48 \pm 0.13$ (Synergism) \\
MTX & MOS & $1.52 \pm 0.73$ (Additive) & $1.15 \pm 0.92$ (Additive) \\
& LM8 & $0.97 \pm 0.17$ (Additive) & $0.93 \pm 0.31$ (Additive) \\
& MOS & $0.14 \pm 0.11$ (Synergism) & $0.72 \pm 0.65$ (Additive) \\
\multirow{2}{*}{ PAC } & LM8 & $1.06 \pm 0.19$ (Additive) & $1.24 \pm 0.39$ (Additive) \\
& MOS & $0.07 \pm 0.05$ (Synergism) & $0.21 \pm 0.27$ (Synergism) \\
GEM & LM8 & $0.03 \pm 0.07$ (Synergism) & $0.52 \pm 0.21$ (Synergism) \\
& MOS & $0.18 \pm 0.10$ (Synergism) & $0.26 \pm 0.31$ (Synergism) \\
& LM8 & $0.67 \pm 0.12$ (Synergism) & $0.53 \pm 0.22$ (Synergism) \\
\hline
\end{tabular}
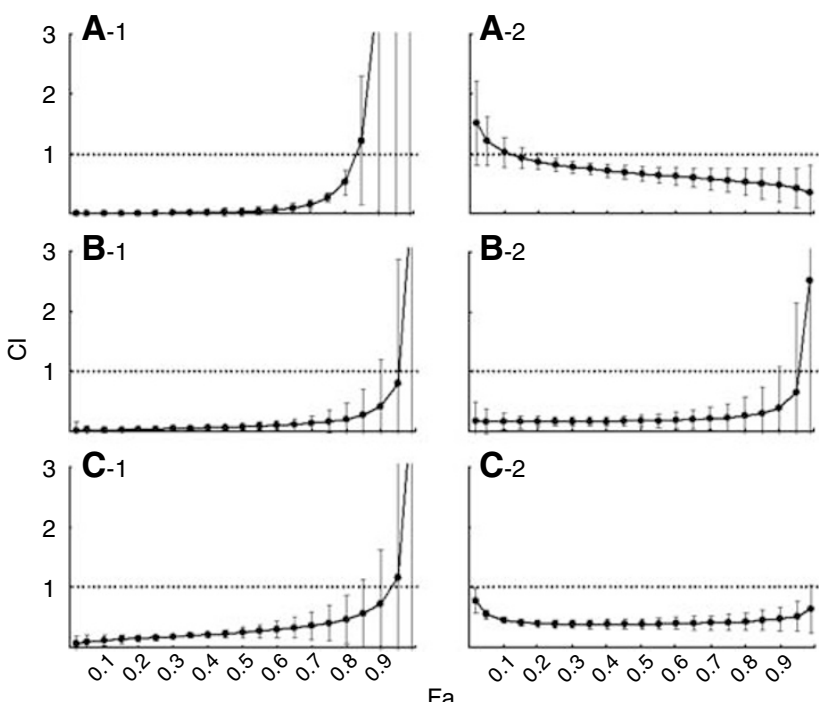

Figure 2 Effect of the concurrent treatment with $\mathrm{ZOL}$ and anticancer agents on murine osteosarcoma cell lines growth. The combination index $(\mathrm{Cl})$ is plotted as a function of the fraction affected $(\mathrm{Fa})$, which represents the percentage of growth inhibition (e.g. $0.5=50 \%$ ) and was evaluated using the MTT assay. Combinations of multiple equipotent agent concentrations were analysed for synergistic $(\mathrm{Cl}<\mathrm{I})$, additive $(\mathrm{Cl}=\mathrm{I})$, or antagonistic $(\mathrm{Cl}>\mathrm{I})$ effects. Concurrent exposure to PAC $(-\mathrm{I})$ and GEM $(-2)$ on LM8 cells $(\mathbf{A})$, MOS cells $(\mathbf{B})$ and MOS/ADR cells $(\mathbf{C})$. Data are presented as the mean \pm s.d. of three independent experiments.

demonstrated only in LM8 cells. To investigate the possible mechanisms underlying the synergistic interaction between $\mathrm{ZOL}$ and PAC or GEM, we analysed the effects of these anticancer agents on cell cycle. Alterations of cell cycle by $24 \mathrm{~h}$ exposure to ZOL, PAC or GEM in MOS and LM8 cells are summarised in Table 3. After $24 \mathrm{~h}$ exposure to ZOL at $2.0 \mu \mathrm{M}$ for MOS cells or at $15 \mu \mathrm{M}$ for LM8 cells, the percentages of cells in the $\mathrm{S}$ phase increased without significant increase in the sub- $\mathrm{G}_{1}$ phase. After $24 \mathrm{~h}$ exposure to PAC at $25 \mathrm{~nm}$ for MOS or at $10 \mathrm{nM}$ for LM8 cells, the percentages of cells in the $G_{1}$ and $S$ phases decreased and those in the $G_{2} / M$ and sub- $G_{1}$ phase increased. After $24 \mathrm{~h}$ exposure to $25 \mathrm{nM}$ GEM, the percentages of cells in the $S$ and $G_{2}$ phases decreased, and those in sub- $G_{1}$ and $G_{1}$ phases increased.

\section{Combined effects of ZOL with PAC or GEM on the alterations of cell cycle}

When MOS cells were treated with $0.5 \mu \mathrm{M}$ ZOL combined with $5 \mathrm{nM}$ $\mathrm{PAC}$ for $24 \mathrm{~h}$, there was an increase in the proportion of MOS cells 

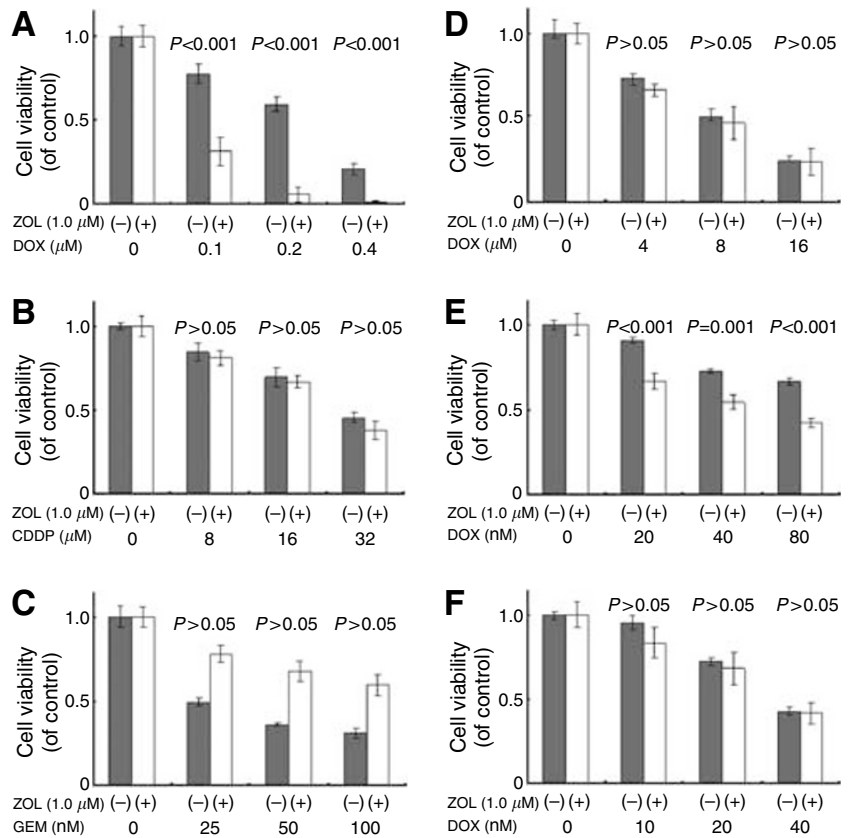

Figure 3 Effect of sequential combinations of $\mathrm{ZOL}$ and anticancer agents on MOS cell line growth. MOS cells were pretreated with $1.0 \mu \mathrm{M}$ $\mathrm{ZOL}$ for $24 \mathrm{~h}$, washed thrice in PBS and then treated for $48 \mathrm{~h}$ with the second anticancer agents, namely, $\operatorname{DOX}(\mathbf{A}), \operatorname{CDDP}(\mathbf{B}), \operatorname{MTX}(\mathbf{C}), \mathrm{IM}$ (D), PAC (E) or GEM (F). Data are presented as the mean \pm s.d. of three independent experiments.
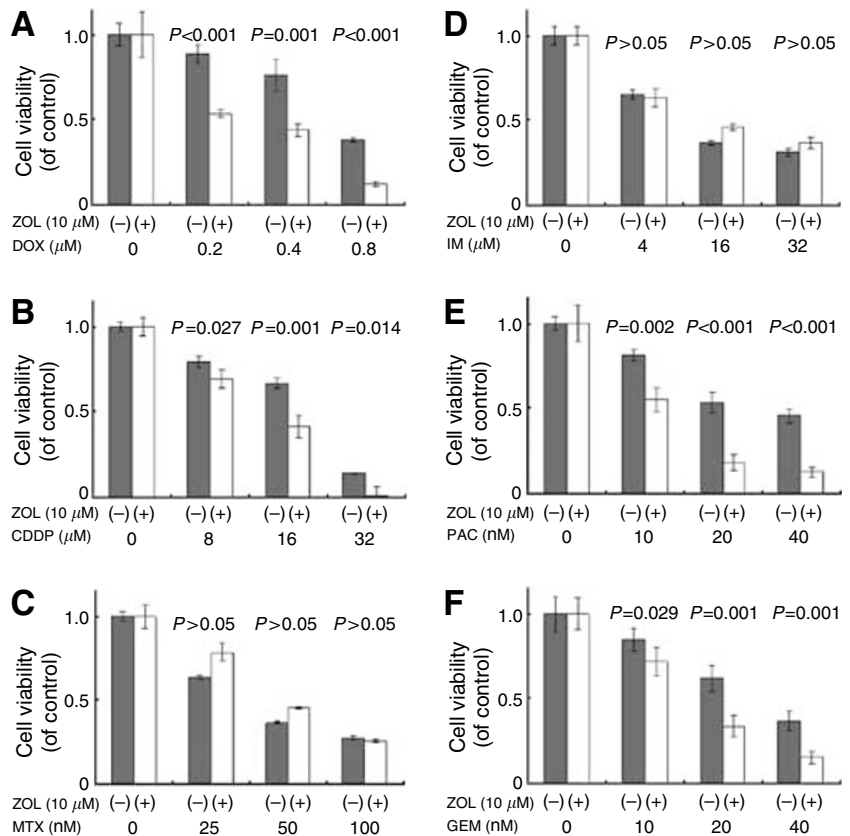

Figure 4 Effect of sequential combinations of $\mathrm{ZOL}$ and anticancer agents on LM8 cell line growth. LM8 cells were pretreated with $10 \mu \mathrm{M} Z \mathrm{OL}$ for $24 \mathrm{~h}$, washed thrice in PBS and then treated for $48 \mathrm{~h}$ with the second anticancer agents, namely, DOX (A), CDDP (B), MTX (C), IM (D), PAC (E) or GEM (F). Data are presented as the mean \pm s.d. of three independent experiments.

in S-phase despite the fact that neither drug at this concentration affected the cell cycle when used individually (Figure 5A-1-4). These results are same as on LM8 cells treated with $10 \mu \mathrm{M}$ ZOL combined with $5 \mathrm{nM}$ PAC for $24 \mathrm{~h}$ (Figure 5B-1-4). These suggested
Table 3 Summary of cell cycle distribution (\%) following $24 \mathrm{~h}$ agent treatment in osteosarcoma cells (A: MOS cells, B: LM8 cells)

\begin{tabular}{lcccc}
\hline & Sub-G & $\mathbf{G}_{\mathbf{~}}$ & $\mathbf{S}$ & $\mathbf{G}_{\mathbf{2}} \mathbf{M}$ \\
\hline A-I: untreated MOS cells & 3.7 & 46.2 & 30.8 & 16.8 \\
A-2: ZOL (2.0 $\mu$ M) & 5.5 & 32.1 & 46.3 & 12.6 \\
A-3: PAC (25 nM) & 17.5 & 19.7 & 18.8 & 28.9 \\
B-I: untreated LM8 cells & 4.7 & 46.2 & 25.0 & 21.4 \\
B-2: ZOL (I5 $\mu$ M) & 6.6 & 30.0 & 39.0 & 21.0 \\
B-3: PAC (IO nM) & 27.0 & 2.4 & 10.2 & 47.0 \\
B-4: GEM (25 nM) & 25.1 & 30.7 & 25.6 & 10.4 \\
\hline
\end{tabular}

that when ZOL is combined with PAC, PAC might augment the ability of ZOL to produce S-phase arrest. When LM8 cells were treated with $10 \mu \mathrm{M}$ ZOL combined with $10 \mathrm{nM}$ GEM for $24 \mathrm{~h}$, there was an increase in the ratio of LM8 cells in sub- $G_{1}$, although neither drug concentration produced this effect when applied by itself (Figures 5B-2, 5 and 6). This indicated that when combined with GEM, ZOL might augment the sub- $\mathrm{G}_{1}$ effect of GEM on the cell cycle.

\section{DISCUSSION}

Our previous study revealed that when used as single agents, the third-generation BPs, YM175 and YM529, possess antitumour activity in an osteosarcoma cell line in vitro, and when these effects were compared with the effect of BPs on other tumour cell lines, YM175 and YM529 produce stronger antitumour effects on the murine osteosarcoma cell line than other cancer cell lines. However, the effects of YM175 and YM529 were impaired against a P-gp-overexpressing osteosarcoma cell line (Horie et al, 2006). As YM529 has not been made clinically available yet we investigated the anti-osteosarcoma effects of $\mathrm{ZOL}$, another thirdgeneration BP, which is clinically available and as potent as YM529 at inhibiting bone resorption in vivo (Widler et al, 2002).

To investigate specificity of ZOL against osteosarcoma cells, we examined the inhibitory effects of ZOL against both osteosarcoma cell lines and normal cells such as murine osteoblast and NHDF cells. Moreover, to test the hypothesis that ZOL could have chelating action, we examined the growth-inhibitory effects of the most commonly used chelating agent EDTA on osteosarcoma cell lines. Lower concentration of ZOL did not inhibit the growth of normal cells, and $1000 \mu \mathrm{M}$ EDTA did not inhibit the growth of osteosarcoma cells (Figure 1A). If the effect of ZOL depends on its chelating mechanism, divalent cations can inhibit it. However, the antiproliferative effect of ZOL was reported to be strengthened by the addition of divalent cations, while that of EDTA was weakened by the addition of divalent cations (Reinholz et al, 2000). These findings suggest that ZOL selectively inhibited the growth of osteosarcoma cells independently by its chelating effects.

The interaction between ZOL and P-gp is still controversial. P-gp-overexpressing MOS/ADR cell line was 4.6 times more resistant to ZOL than its parental MOS cell line (Table 1, Figure $1 \mathrm{C}$ ). Moreover, $1 \mu \mathrm{m}$ verapamil augmented the effects of ZOL on MOS/ADR cells and restored the sensitivity of MOS/ADR cells to almost same level of its parental cell line, MOS. These findings suggested that the effects of $\mathrm{ZOL}$ in osteosarcoma cells were affected by P-gp. However, we have previously reported that the antitumour effects of ZOL against leukaemic cell lines are not affected by P-gp (Kuroda et al, 2003). This discrepancy could be explained by the differences on the activity of $\mathrm{ZOL}$ against leukaemic cells and osteosarcoma cells. Both $\mathrm{IC}_{50} \mathrm{~s}$ of $\mathrm{ZOL}$ against parental and P-gp-overexpressing leukaemic cells are above $60 \mu \mathrm{M}$, whereas of those against osteosarcoma cells were much less. It could, therefore, be argued that in the cell lines that we used, the 


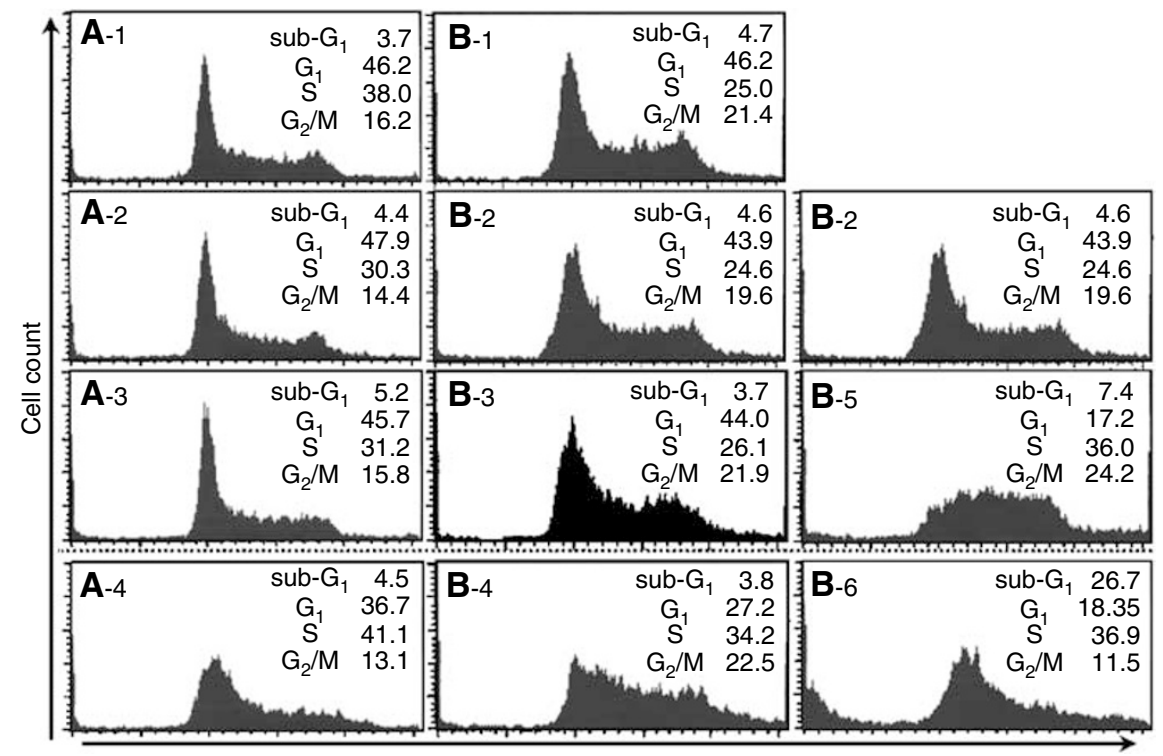

DNA content

Figure 5 Cell cycle analysis of combined treatment of ZOL with PAC or GEM. The effect of agents on the cell cycle was evaluated by flow cytometry of osteosarcoma cells that had been exposed to different agent concentrations for $24 \mathrm{~h}$. MOS cells $(\mathbf{A})$; untreated $(-\mathrm{I}), 0.5 \mu \mathrm{M} Z \mathrm{OL}(-2), 5 \mathrm{nM}$ PAC ( -3$)$, $0.5 \mu \mathrm{M}$ ZOL with $5 \mathrm{nM}$ PAC (-4) and LM8 cells (B); untreated $(-1)$, I0 $\mu \mathrm{M}$ ZOL (B-2), $5 \mathrm{nM} \mathrm{PAC} \mathrm{(-3),} \mathrm{I0} \mu \mathrm{M} Z \mathrm{OL}$ with $5 \mathrm{nM}$ PAC (-4), I0 nM GEM (-5) and $10 \mu \mathrm{M} Z \mathrm{ZL}$ with $10 \mathrm{nM}$ GEM (-6). Cell cycle distribution (\%) of each agent is shown. The data shown are representative of three independent experiments.

efflux pump enabled the elimination of small amounts of BPs, although it did not work efficiently for large quantities of ZOL.

According to a previous study evaluating ZOL efficacy for the treatment of osteoporosis (Chen et al, 2002), peak serum concentrations were in the range of $1-3 \mu \mathrm{M}$ and maintained for only a few hours. As $\mathrm{IC}_{50}$ s of ZOL for MOS and LM8 cells are 1.56 and $7.36 \mu \mathrm{M}$, respectively, it is likely that the effect of ZOL alone might be insufficient. Moreover, ZOL is less effective against P-gp-overexpressing osteosarcoma cells. Therefore, we examined the combined effects of ZOL with other anticancer agents. In the present study, we examine the combined effects of ZOL with commonly used anti-osteosarcoma agents such as DOX, CDDP and MTX. CDDP has been reported to augment synergistically the effects of ZOL (Matsumoto et al, 2005). We also examine the combined effects of $\mathrm{ZOL}$ with other three agents that are undergoing clinical trial or have been examined in vitro experiments for osteosarcoma cells, such as IM (McGary et al, 2002), PAC (Verweij et al, 2000) and GEM (Okuno et al, 2002). IM specifically inhibits selected tyrosine kinase receptors, including platelet-derived growth factor (PDGF) and c-Kit. As osteosarcoma expresses low levels of c-Kit, but abundant levels of the PDGF receptor (McGary et al, 2002), IM might be a promising candidate for osteosarcoma therapeutics. Both PAC, a mitotic spindle toxin and GEM, a nucleoside analogue, are in phase 2 clinical trails for osteosarcoma (Verweij et al, 2000; Okuno et al, 2002).

The concurrent treatment of ZOL with DOX or CDDP resulted in additive or synergistic growth inhibition of osteosarcoma cell lines. Interestingly, concurrent exposure to ZOL significantly augmented the effects of PAC and GEM in these cell lines. When MOS or LM8 cells were treated with ZOL combined with PAC for $24 \mathrm{~h}$, there was an increase in the proportion of MOS cells in S-phase despite the fact that neither drug at this concentration affected the cell cycle when used individually (Figure 5A, B-1-4). These suggested that when ZOL is combined with PAC, PAC might augment the ability of ZOL to produce S-phase arrest, resulting the combined effects. Similarly, when LM8 cells were treated with ZOL combined with GEM at the concentration which had no effects on the alteration on cell cycle for $24 \mathrm{~h}$, there was a significant increase in the ratio of cells in sub- $\mathrm{G}_{1}$ (Figures $5 \mathrm{~B}-2,5$ and 6 ). This indicated that when combined with GEM, ZOL might induce more apoptotic cells. These synergistic effects of ZOL depend on the doses and the osteosarcoma cell line studied.

These results may have therapeutic application, particularly for enhancing the efficacy of DOX or CDDP that cannot be administered at higher dosages because of toxicity. Recently, the combined effects of ZOL and PAC (Jagdev et al, 2001; NevilleWebbe et al, 2006) or GEM (Budman and Calabro, 2006) have been reported. However, the precise mechanism by which ZOL enhances the effects of these agents is not yet fully understood. We tried to investigate the mechanism of combined effects with ZOL and other agents. As we have previously reported in leukaemic cells, ZOL inhibited the progression of osteosarcoma cells in S-phase (Table 3). Two agents that showed significant combined effects with ZOL such as PAC and GEM revealed different effects of the alteration of cell cycle in osteosarcoma cells. PAC accumulated cells in $\mathrm{G}_{2} / \mathrm{M}$ phase, resulting the induction of apoptosis (Das et al, 2001), while GEM seemed to induce apoptosis in S phase (Shi et al, 2001) (Table 3). These findings suggest that it is difficult to predict which agent becomes a good partner for ZOL based on its activity on the alteration of cell cycle. Further studies will be required to more fully elucidate these mechanisms.

P-gp-mediated multi-drug resistance is crucial for cancer treatment. Although many P-gp inhibitors have been identified, none of them have been proven clinically useful without side effects, combination chemotherapy is one of the strategies to overcome the P-gp mediated multi-drug resistance (Ozben, 2006). Based on the additional effect of verapamil on the ZOL- or DOXinduced growth inhibition of MOS/ADR cells (Figure 1B and C), $\mathrm{P}$-gp was suggested to have some role in ZOL-resistance. Because PAC is a substrate for P-gp (Horwitz et al, 1993) (Table 1), it is suggested that the coadministration of PAC and ZOL show the inhibitory effect on the cell growth of MOS/ADR cells by similar mechanism with the addition of verapamil. In the present study, we have found the four-fold resistance against GEM in the MOS/ ADR cells in comparison with the parental cells (Table 1). However, the additional effect of GEM on the ZOL-induced inhibitory effect on cell growth was observed both in the parental MOS and MOS/ADR cells (Figure 2B and $\mathrm{C}$ ). Therefore, the 
coadministration of ZOL may independently inhibit the cell growth of these cell lines in addition to GEM, which shows its effects via deoxycytidine kinase pathway (Blackstock et al, 2001). The mechanism of these combined effects should be more investigated. However, ZOL plus PAC or GEM might become a good application for multi-drug-resistant osteosarcoma cells.

We also investigated the sequential combined effects of ZOL with other anticancer agents. MOS and LM8 cells were pretreated for $24 \mathrm{~h}$ with lower concentration of $\mathrm{ZOL}$, and that concentration did not alter the cell cycle and increase the percentage of apoptotic cells in these cells, and significantly augmented the effects of DOX in both MOS and LM8 cells (Figure $3 \mathrm{~A}$ and 4A), and of CDDP in LM8 cells (Figure 4B). In contrast, ZOL combined with MTX in both cell lines showed antagonistic effects (Figure 3C and 4C). This antagonistic effect of MTX was also seen in leukaemic cells (Kimura et al, 2004). Because MTX activity was changed by the sensitivity of cells and the pharmacokinetics of the drugs, MTX has major cytotoxic effects on cells in the $S$ phase and accumulates in cells in the $G_{1}$ to early $S$ phase and later into the $G_{2} / M$ phase (Lorico et al, 1990; Yamauchi et al, 2005). On the contrary, ZOL has major cytotoxic effects in the $\mathrm{S}$ phase and accumulates in cells in the late $S$ and early $G_{2}$ phases (Kuroda et al, 2003). If cells were treated MTX followed by ZOL, the combined effect may be observed to augment each other. But in the present study, the combined treatments of ZOL with MTX have been carried out. It has been noted that one agent might reduce the cytotoxicity of the

\section{REFERENCES}

Asai T, Ueda T, Itoh K, Yoshioka K, Aoki Y, Mori S, Yoshikawa H (1998) Establishment and characterization of a murine osteosarcoma cell line (LM8) with high metastatic potential to the lung. Int $J$ Cancer 76: $418-422$

Bacci G, Longhi A, Versari M, Mercuri M, Briccoli A, Picci P (2006) Prognostic factors for osteosarcoma of the extremity treated with neoadjuvant chemotherapy: 15-year experience in 789 patients treated at a single institution. Cancer 106: $1154-1161$

Blackstock AW, Lightfoot H, Case LD, Tepper JE, Mukherji SK, Mitchell BS, Swarts SG, Hess SM (2001) Tumor uptake and elimination of $2^{\prime}, 2^{\prime}$ difluorodeoxycytidine (gemcitabine) after deoxycytidine kinase gene transfer: correlation with in vivo tumor response. Clin Cancer Res 7: $3263-3268$

Budman DR, Calabro A (2006) Zoledronic acid (Zometa) enhances the cytotoxic effect of gemcitabine and fluvastatin: in vitro isobologram studies with conventional and nonconventional cytotoxic agents. Oncology 70: $147-153$

Chen T, Berenson J, Vescio R, Swift R, Gilchick A, Goodin S, LoRusso P, Ma P, Ravera C, Deckert F, Schran H, Seaman J, Skerjanec A (2002) Pharmacokinetics and pharmacodynamics of zoledronic acid in cancer patients with bone metastases. J Clin Pharmacol 42: 1228-1236

Choi CH, Sedlacek RS, Suit HD (1979) Radiation-induced osteogenic sarcoma of $\mathrm{C} 3 \mathrm{H}$ mouse: effects of Corynebacterium parvum and WBI on its natural history and response to irradiation. Eur J Cancer 15: $433-442$

Chow KU, Ries J, Weidmann E, Pourebrahim F, Napieralski S, Stieler M, Boehrer S, Rummel MJ, Stein J, Hoelzer D, Mitrou PS (2000) Induction of apoptosis using $2^{\prime}, 2^{\prime}$ difluorodeoxycytidine (gemcitabine) in combination with antimetabolities or anthracyclines on malignant lymphatic and myeloid cells. Antagonism or synergism depends on incubation schedule and origin of neoplastic cells. Ann Hematol 79: 485-492

Das GC, Holiday D, Gallardo R, Haas C (2001) Taxol-induced cell cycle arrest and apoptosis: dose-response relationship in lung cancer cells of different wild-type p53 status and under isogenic condition. Cancer Lett 165: $147-153$

Evdokiou A, Labrinidis A, Bouralexis S, Hay S, Findlay DM (2003) Induction of cell death of human osteogenic sarcoma cells by zoledronic acid resembles anoikis. Bone 33: $216-228$

Fleisch H (2002) Development of bisphosphonates. Breast Cancer Res 4: $30-34$

Hansen MB, Nielsen SE, Berg K (1989) Re-examination and further development of a precise and rapid dye method for measuring cell growth/cell kill. J Immunol Methods 119: 203-210 other agent by preventing cells from entering the specific phase in which the cells are most sensitive to the other agent. Although the reason for this antagonism is not fully clarified, the simultaneous administration of ZOL with MTX might be counterproductive not only for treatment of osteosarcoma but also for other cancers. Methotrexate is commonly used in various chemotherapy regimens (Kummel et al, 2006). Therefore, the clinical use of ZOL should be evaluated carefully to avoid inadequate interaction even when ZOL is indicated for other reasons, such as metastatic involvement of the bone.

In conclusion, the combination of ZOL with DOX, CDDP, PAC or GEM may be effective against murine osteosarcoma cells, compared to the use of any of these agents alone. These results provide a basis for conducting further studies using human osteosarcoma cell lines or fresh osteosarcoma cells obtained from patient resection samples and such studies ultimately will provide a rationale for the preclinical/clinical evaluation of the antitumour activity of ZOL in combination with other anticancer agents.

\section{ACKNOWLEDGEMENTS}

We thank Dr Masuda (Kyoto University) for his critical reading of this manuscript. This work was partly supported by a Grant-in aid (15790796) for Scientific Research from the Ministry of Education, Culture, Sports, Science and Technology of Japan (to HM).

Heymann D, Ory B, Blanchard F, Heymann MF, Coipeau P, Charrier C, Couillaud S, Thiery JP, Gouin F, Redini F (2005) Enhanced tumor regression and tissue repair when zoledronic acid is combined with ifosfamide in rat osteosarcoma. Bone 37: 74-86

Horie N, Murata H, Nishigaki Y, Matsui T, Segawa H, Nogawa M, Yuasa T, Kimura S, Maekawa T, Fushiki S, Kubo T (2006) The third-generation bisphosphonates inhibit proliferation of murine osteosarcoma cells with induction of apoptosis. Cancer Lett 238: $111-118$

Horwitz SB, Cohen D, Rao S, Ringel I, Shen HJ, Yang CP (1993) Taxol: mechanisms of action and resistance. J Natl Cancer Inst Monogr 15: $55-61$

Jagdev SP, Coleman RE, Shipman CM, Rostami-H A, Croucher PI (2001) The bisphosphonate, zoledronic acid, induces apoptosis of breast cancer cells: evidence for synergy with paclitaxel. Br J Cancer 84: 1126-1134

Kimura S, Kuroda J, Segawa H, Sato K, Nogawa M, Yuasa T, Ottmann OG, Maekawa T (2004) Antiproliferative efficacy of the third-generation bisphosphonate, zoledronic acid, combined with other anticancer drugs in leukemic cell lines. Int J Hematol 79: 37-43

Kimura S, Maekawa T, Hirakawa K, Murakami A, Abe T (1995) Alterations of $c$-myc expression by antisense oligodeoxynucleotides enhance the induction of apoptosis in HL-60 cells. Cancer Res 55: 1379-1384

Kubista B, Trieb K, Sevelda F, Toma C, Arrich F, Heffeter P, Elbling L, Sutterluty H, Scotlandi K, Kotz R, Micksche M, Berger W (2006) Anticancer effects of zoledronic acid against human osteosarcoma cells. J Orthop Res 24: $1145-1152$

Kubo T, Shimose S, Matsuo T, Tanaka K, Yasunaga Y, Sakai A, Ochi M (2006) Inhibitory effects of a new bisphosphonate, minodronate, on proliferation and invasion of a variety of malignant bone tumor cells. J Orthop Res 24: 1138-1144

Kummel S, Krocker J, Kohls A, Breitbach GP, Morack G, Budner M, Blohmer JU, Elling D (2006) Randomised trial: survival benefit and safety of adjuvant dose-dense chemotherapy for node-positive breast cancer. Br J Cancer 94: 1237-1244

Kuroda J, Kimura S, Segawa H, Kobayashi Y, Yoshikawa T, Urasaki Y, Ueda T, Enjo F, Tokuda H, Ottmann OG, Maekawa T (2003) The third-generation bisphosphonate zoledronate synergistically augments the anti-Ph+ leukemia activity of imatinib mesylate. Blood 102: $2229-2235$

Link MP (1993) Preoperative and adjuvant chemotherapy in osteosarcoma. In Frontiers of Osteosarcoma Research: Interdisciplinary Survey of Clinical and Research Advances Novak JF, Mcmaster JH (eds) pp $41-$ 49. Seattle: Hogrefe and Huber 
Lorico A, Boiocchi M, Rappa G, Sen S, Erba E, D’Incalci M (1990) Increase in topoisomerase-II-mediated DNA breaks and cytotoxicity of VP16 in human U937 lymphoma cells pretreated with low doses of methotrexate. Int J Cancer 45: $156-162$

Matsumoto S, Kimura S, Segawa H, Kuroda J, Yuasa T, Sato K, Nogawa M, Tanaka F, Maekawa T, Wada H (2005) Efficacy of the third-generation bisphosphonate, zoledronic acid alone and combined with anti-cancer agents against small cell lung cancer cell lines. Lung Cancer 47: 31 - 39

McGary EC, Weber K, Mills L, Doucet M, Lewis V, Lev DC, Fidler IJ, Bar-Eli M (2002) Inhibition of platelet-derived growth factor-mediated proliferation of osteosarcoma cells by the novel tyrosine kinase inhibitor STI571. Clin Cancer Res 8: 3584-3591

Neville-Webbe HL, Evans CA, Coleman RE, Holen I (2006) Mechanisms of the synergistic interaction between the bisphosphonate zoledronic acid and the chemotherapy agent paclitaxel in breast cancer cells in vitro. Tumour Biol 27: $92-103$

Okuno S, Edmonson J, Mahoney M, Buckner JC, Frytak S, Galanis E (2002) Phase II trial of gemcitabine in advanced sarcomas. Cancer 94: 3225-3229

Ory B, Heymann MF, Kamijo A, Gouin F, Heymann D, Redini F (2005) Zoledronic acid suppresses lung metastases and prolongs overall survival of osteosarcoma-bearing mice. Cancer 104: $2522-2529$

Ozben T (2006) Mechanisms and strategies to overcome multiple drug resistance in cancer. FEBS Lett 580: 2903 - 2909

Reinholz GG, Getz B, Pederson L, Sanders ES, Subramaniam M, Ingle JN, Spelsberg TC (2000) Bisphosphonates directly regulate cell proliferation, differentiation, and gene expression in human osteoblasts. Cancer Res 60: $6001-6007$

Segawa H, Kimura S, Kuroda J, Sato K, Nogawa M, Yuasa T, Yokota A, Hodohara K, Fujiyama Y, Maekawa T (2005) The anti-leukemic efficacy of the third generation bisphosphonate ONO5920/YM529. Leuk Res 29: $451-457$

Shi Z, Azuma A, Sampath D, Li YX, Huang P, Plunkett W (2001) S-Phase arrest by nucleoside analogues and abrogation of survival without cell cycle progression by 7-hydroxystaurosporine. Cancer Res 61: 1065-1072
Takahashi N, Akatsu T, Udagawa N, Sasaki T, Yamaguchi A, Moseley JM, Martin TJ, Suda T (1988) Osteoblastic cells are involved in osteoclast formation. Endocrinology 123: $2600-2602$

Takeshita H, Gebhardt MC, Springfield DS, Kusuzaki K, Mankin HJ (1996) Experimental models for the study of drug resistance in osteosarcoma: p-glycoprotein-positive, murine osteosarcoma cell lines. J Bone Joint Surg 78-A: $366-375$

Tenta R, Sourla A, Lembessis P, Koutsilieris M (2006) Bone-related growth factors and zoledronic acid regulate the PTHrP/PTH.1 receptor bioregulation systems in MG-63 human osteosarcoma cells. Anticancer Res 26: $283-291$

Unni KK (1996) Dahlin's BONE TUMORS General Aspects and Date on 11,0809 Cases 5th edn, pp 143-183. Philadelphia: Lippincott

Verweij J, Lee SM, Ruka W, Buesa J, Coleman R, van Hoessel R, Seynaeve C, di Paola ED, van Glabbeke M, Tonelli D, Judson IR (2000) Randomized phase II study of docetaxel $v s$ doxorubicin in first- and second-line chemotherapy for locally advanced or metastatic soft tissue sarcomas in adults: a study of the european organization for research and treatment of cancer soft tissue and bone sarcoma group. J Clin Oncol 18: $2081-2086$

Widler L, Jaeggi KA, Glatt M, Muller K, Bachmann R, Bisping M, Born AR, Cortesi R, Guiglia G, Jeker H, Klein R, Ramseier U, Schmid J, Schreiber G, Seltenmeyer Y, Green JR (2002) Highly potent geminal bisphosphonates. From pamidronate disodium (Aredia) to zoledronic acid (Zometa). J Med Chem 45: 3721-3738

Yamauchi A, Ichimiya T, Inoue K, Taguchi Y, Matsunaga N, Koyanagi S, Fukagawa T, Aramaki H, Higuchi S, Ohdo S (2005) Cell-cycle-dependent pharmacology of methotrexate in HL-60. J Pharmacol Sci 99: $335-341$

Yuasa T, Nogawa M, Kimura S, Yokota A, Sato K, Segawa H, Kuroda J, Maekawa T (2005) A third-generation bisphosphonate, minodronic acid (YM529), augments the interferon alpha/beta-mediated inhibition of renal cell cancer cell growth both in vitro and in vivo. Clin Cancer Res 11: $853-859$ 